\title{
IMPROVEMENT OF SUGAR-CANE BY SELECTION AND HYBRIDIZATION.
}

\author{
By F. A. Stockdale, B.A., Imperial Department of Agriculture for the \\ West Indies.
}

Probably no subject is of so much importance to planters of sugar cane as that relating to the introduction and trial of new varieties. It would appear that the first announcement respecting the possibility of raising seedling canes in the West Indies was made at various times between 1859 and 1888 . A similar announcement was made in Java in 1887. Since the latter year, their cultivation has been intelligently followed up and much improvement in the sugar cane has resulted. Varieties have been raised which are capable of resisting attacks of disease which destroyed the older forms, and this has led to a demand, still imperfectly satisfied, for the better kinds of canes. That climate and soil are the paramount influences affecting the sugar producing capacity of different varieties has clearly been shown by the difference in yields and other characteristics manifested by the same cane in different localities. The variety of soil and climatic conditions of the West Indies renders it necessary to have many kinds of cane differing in their requirements, for it could not be expected to produce one single cane to meet the requirements of all situations. Several experimental plats, in the different islands, were started to produce better canes, and the value of the results obtained must be very gratifying to those who have spent much time over these experiments, for the seedling canes produced at Barbados by Professor Harrison and Mr. Bovell and by Mr. Jenman and Professor Harrison at British Guiana are now well known in most of the sugar-producing countries of the world. In striving to produce improved kinds of canes many features must be taken into account, amongst which the most important may be their germinative power, behavior under excessive dryness or moisture, resistance to disease, rattooning power, milling qualities, fuel-producing property (depending on the percentage of fiber), quantity of juice and its content of sugar. The last of these features is, no doubt, the one which claims the most notice, for maximum productiveness in most cases has not yet been reached and much is still to be gained in this direction.

The earlier method adopted for producing seedling canes was the careful selection of casually produced seedlings. A later step was the identity of seedlings from the seed-bearing parent. A further stage was raising seedlings from canes planted in alternate rows so that the pollen-bearing parent might be identified as well as the seed-bearing parent. Experiments in this direction have been carefully carried on at Java, Barbados and British Guiana.

The selection method practised in British Guiana was well described under separate heads by Professor J. B. Harrison at the last West Indian Agricultural Conference, (see West Indian Bulletin, Vol. V, p. 337) as follows:

First selection of parent varieties for seed producers. 
Second selection of the more vigorous of the seedlings obtained from them for field propagation.

Third selection of the varieties growing under field conditions by the cultural characteristics. acters.

Fourth selection from these selected sorts by their analytical char-

Fifth selection. The third and fourth methods are repeated with plants raised from the tops of the varieties selected under the fourth selection, and this is done repeatedly during the cultivation of them from plants to second and third rattoons. As the method of cultivation in British Guiana renders it necessary for canes to have good rattooning powers to be of service as sugar producers, we lay more stress on the selection from rattoons than from plants.

Sixth selection. Those varieties which have been selected are next grown on plats of about one-twentieth acre, side by side and under identical conditions of cultivation and manuring. On these their peculiarities are carefully watched, and out of batches of 40 or so selected for this trial probably not more than a dozen will be retained in cultivation as third or fourth rattoons.

Seventh selection. During the course of the fifth and sixth selections, several of the varieties finally retained in cultivation will have been selected by planters by large-scale cultivation. These and a few others selected by ourselves are next examined by means of manurial experiments. Plats of about one-half acre are divided into smaller plats, and upon these the varieties are raised under varying systems of manuring. Some of the plats of every kind are manured with phosphates, and perhaps potash $/$ others are not. Some of each are grown without any nitrogenous manures; others with increasing quantities of nitrogen. It has been found that the mean results of a kind under the varying kinds of manuring apparently offer the most reliable figures as to comparative value we can obtain on small-scale experiments.

In Barbados, the selection of seedling canes, similar to that of British Guiana, has been practised for some years. Recently, however, an effort has been made to reduce the time in selecting seedlings by two years, by means of irrigation. The method adopted is as follows:

After the canes are pricked out into pots and grown to about one foot in height, they are planted in the field about April and May of each year and irrigated. The following May, the canes are first of all selected for their field characters, and then crushed and tested for their saccharine content. The stools of those canes which are rich in sucrose and have given a heavy tonnage are taken up, divided in half, and replanted under irrigation, and the following December the canes from these stools are cut up and planted in the experiment plats and start their career in the successive stages of selection until the best of them-generally a very small percentage-attain the standard of being tested on acre plats.

At the Barbados and other experiment stations, the canes are grown under the ordinary conditions existing upon the estates where 
they are cultivated. The plats in which the seedlings are grown are arranged in duplicate: Each plat consists of 100 stools of canes arranged in 4 rows of 25 canes. For planting the next year, the canes from the outside rows are utilized; whereas the inner 30 stools are cut, weighed and sampled. By recording the result of the inner rows only, the effects of one variety upon the growth of another and less vigorous variety are therefore eliminated. One hundred pounds of each sample are then crushed in the laboratory mill, the juice and megass are weighed, and the juice is analyzed, and from the data secured the results are calculated to the acre.

By means of this rigorous selection several good varieties have been raised, but a large percentage of the seedlings thus produced have proved to be worthless. The fixing of the good varieties is rendered easy as plants raised from cuttings come true to the parent and therefore do not necessitate additional selection year-after year. By this means thousands of seedlings have been raised every year, and, after careful trial on experimental plats in different parts of the West Indies for several years in comparison with standard canes, the best are selected and recommended to planters for final trial under estate conditions. It, therefore, takes several years before a seedling cane has been sufficiently investigated to deserve recommendation to the planters and then it must be left to the planter to finally select those which he thinks suitable for his cultivation, as a seedling may give very good results in one soil but prove an utter failure in another.

The difficulty, however, that had to be contended with by this method was that, although the seed-bearing parent was known and registered, the male parent was unknown, and therefore a vast majority of the seedlings were less valuable than the seed-bearing or female parent form originally selected. With a view to reducing this difficulty to a minimum, crossing has been resorted to in the hope that some of the offspring would combine the good qualities of the two parents.

By this means, poth parents are carefully selected, both have to be high in saccharine contents and both have to possess good field characters. Hybrids generally possess a more vigorous growth, which provides suitable conditions to make it possible to obtain advantages resulting from the mingling of ancestral plasma masses. Therefore, by hybridization, it is hoped to combine some of the desirable characters of both parents and, therefore, to produce canes which can be highly recommended.

The first method by which hybridization was effected in the West Indies (and here it was that the first systematic attempt was made to obtain hybrids of sugar cane) is what might be called the natural method. Two good varieties known to arrow at the same time were planted in adjacent plats. Owing, however, to a large number of varieties being under cultivation, it was found almost impossible to ensure against the risk of pollen coming from an unknown source and therefore this method had to be modified.

The next method adopted was to plant varieties arrowing at the same time side by side in alternate rows, so as to present a chess-board 
pattern, and leave the cross-pollination to chance. Some of the seedlings must have been produced from the parents by fertilization inter se and a certain amount of uncertainty must exist as to the parentage of the resultant seedlings.

The Hon. Sir Daniel Morris, Imperial Commissioner of Agriculture for the West Indies, suggested another method for the hybridization of sugar cane, which is much more practical than those formerly used. Each arrow under experiment is bagged some time before it is ripe and when the pollen reaches maturity the contents of the bags of one variety are shaken (through temporary openings) into the bags of another, which is to be the female parent. If precautions are taken to prevent the access of foreign pollen, this method is a good one and can easily be carried out.

A great advance, however, was made in the hybridization of the sugar cane, when it was found that certain varieties do not produce fertile pollen while the pistil is normal, whereas other canes produce a very large amount of normal pollen.

A great number of the better seedlings of Barbados were examined in the laboratory of the Imperial Department of Agriculture for the West Indies, and the investigations have enabled us to divide these seedlings into three classes: (1) in which the anthers show a large proportion of normal pollen; (2) in which the anthers show a very small proportion of normal pollen; (3) in which the anthers show a moderate proportion of normal pollen. If, therefore, an arrow of a cane producing much normal pollen is bagged with an arrow which produced little fertile pollen, the risk of self fertilization is reduced to a minimum and if fertile seeds are produced by these canes, they will almost certainly be the result of hybridization.

The method now practised is a purely artificial cross pollination, in which the flowers of one variety are emasculated, while still young, and then pollen is transferred from another variety by means of a camel's hair brush. This experiment was successfully carried out by Mr. Lewton-Brain, (now Assistant Director of Vegetable Pathology, Hawaiian Sugar Planters' Association) in November, 1904, when he was mycologist on the staff of the Imperial Department of Agriculture for the West Indies. He worked with some of the best of the Barbados varieties and obtained 5 seedlings, which proved that the raising of hybrid sugar canes by artificial cross fertilization is practicable. These are the first seedlings raised in the West Indies whose parentage is a matter of certainty. They are being carefully propagated and instructive results are expected to follow. The method adopted by Mr. Lewton-Brain is described by him in the "West Indian Bulletin" (Vol. V, pp. 362-3) as follows:

"A strong, movable platform was constructed, 8 feet high, the top being 6 feet by 4 feet. On this, there were boxes of different sizes, which served as tables and stools of varying height. The stamens were removed under the dissecting microscope, and the chief difficulty was found to be that of keeping the spikelets steady under the lens while the work was going on.

Arrows which were just beginning to emerge from the upper leaf- 
sheath were always selected. The cane was bent over carefully to the table and tied firmly to neighboring canes and to the platform. The lower part of the arrow was placed in a clamp, the foot of which was then screwed into the top of the platform. All this had, of course, to be done with the greatest care, so that no undue strain was put upon any part of the cane.

The table and dissecting microscope were then shifted into as convenient a position as possible, and the stamens were removed from about 12 to 20 spikelets, preferably on several branches of the arrow. This operation proved to be of some difficulty and delicacy under field conditions; frequently the stigmatic plumes were removed or injured before the third stamen could be got out. It was found necessary to work with one's back to the sun to avoid the glitter from the glumes and hairs.

The remaining spikelets on the arrow, including, of course, all those that had emerged into the air before the operation, were then removed.

Meanwhile a strong pole, 16 feet high from the ground, had been fixed near the base of the cane. To this, near the top, was fixed a wire cage, sufficiently large to include easily the whole arrow; the cage was made in two halves which were left sufficiently apart to admit the arrow. The cane was now gently and gradually released and the arrow was brought into the cage; this was then closed and covered with fine, strong muslin. The whole was sewn up carefully, and the cane and arrow were tied up to the pole. In some cases, too great strain was put upon the upper part of the cane in the tying, and the arrow dried up. A few days later, when the stigmatic plumes were seen to be turning red and opening out, pollination was performed, and the muslin again sewed up.

The whole process is tedious and one that requires great care and delicacy at every point. Under the conditions, this is not always easy. Even then a sudden gust of wind or a sudden shower of rain may spoil a morning's work.

In view of the success of this work, it was decided this year (1905) to commence systematic attempts to raise new hybrids. Owing to fluctuating variations in some of the new seedlings, only those which had stood the stringent tests on a large scale for a considerable time, were used in the experiments. Of these, B 147 and B 208 were considered the best, and over 400 spikelets of these two varieties were emasculated and pollinated. The method adopted was practically that described above, there being a few slight deviations. The staging was made 1 foot higher so that the cane under experiment did not have to be bent so much from the upright position. The arrow which was to become the seed parent was carefully selected on a cane free from disease, bagged before it began to emerge from the leaf sheath and allowed to remain until at least 6 inches presented itself in the air and to the rays of the sun. It was found that very young spikelets were affected seriously by the sun after they had been operated upon, but if they remained exposed until the glumes were beginning to turn slightly red, they stood the severe handling much better. 
Careful microscopic examination of the flowers at this stage revealed very little mature pollen in the anthers and the stigmata were not in a receptive condition, being still in the white immature state. There could, therefore, be no danger of self-fertilization. It was also found that if the spikelets happened to present a lateral view, the glumes could easily be separated and the anthers removed without rupture. The numerous spikelets are generally arranged in pairs, one being sessile and the other stalked. The sessile spikelets are much larger than those on the stalks, but the slightest touch removed them from the spike, so that most. of the work had to be performed on the stalked spikelets.

Two or three spikelets were left on each spike in order to distribute those emasculated throughout the arrow. The emasculated arrow was then tied securely to the pole and brought into the cage covered with strong muslin. The pollen-bearing arrow was then cut off and a portion of it was tied with the cut end in a bottle containing water to the pole, which was erected to support the cane. By this means, it is possible to keep the pollen-producing arrow from 2 to 5 days and therefore produce a constant relay of fertile pollen for pollination. Each of the spikelets emasculated was pollinated twice by means of a camel's hair brush, a separate brush being used for each variety, when the stigmata appeared.

Each cross was made twice wherever possible, the pollen parents of one being used as the seed parent of the other. Each cross was made in triplicate and at least a dozen spikelets in each arrow were operated upon. Over 600 spikelets have been emasculated and artificially pollinated this year, and it is to be hoped that the results obtained may be such as will be before long appreciated by sugar planters. A concise account is being kept of the crosses performed, and next year it is hoped that a series of investigations with the cytology of the sugar cane will be carried on, with a view of obtaining if possible the right age for pollination.

Experiments have also been carried on by Professor J. P. d'Albuquerque and Mr. J. R. Bovell in Bardados, Professor J. B. Harrison in Demerara and Dr. Francis Watts in Antigua; with the object of ascertaining if a higher saccharine content of a certain variety can be induced by repeatedly selecting plants from the richest plants of that variety. This is usually referred to as chemical selection. The results so far obtained appear to be conflicting, but it seems that a greater yield of sugar will only be induced by careful crossing of the better. varieties.

It is now certain that a class of canes has been raised in the West Indies that possess not only a greater sugar producing quality than the older varieties, but also possess, to a large extent, those qualities which enable them to resist disease, so that the planters are now able to override the obstacles which occurred in the cultivation of the older varieties.

The first object for which seedling canes have been raised has, to a large extent, been accomplished, for these new varieties have now been tested in different localities for a sufficient period of time to 
demonstrate their disease-resisting qualities, and, therefore, now we have to turn to the other qualities which go to form our ideal. . In the selection of varieties for crossing, the sugar producing capacity is all important, but considerable notice should be taken of the field characters, especially when it is generally known that planters have a great objection to many canes, because they do not present a pleasing aspect when in growth.

The introduction of these new seedlings in the West Indies has been fully appreciated not only here, but also in other parts of the world, for Barbados and Demerara seedlings have shown that they are superior in many respects to the home canes in such sugar-producing countries as Louisiana, Queensland, Hawaii, and Cuba.

The Bourbon cane was formerly the standard cane in the West Indies, but the results of experiments on a large scale, "indicate an increased yield per acre of from 12 to 20 per cent over that of the Bourbon." The seedlings that are best known in most parts of the world are D 109, D 74, D 95, B 147, and B 208.

The last two mentioned have successfully stood the test for many years on an estate scale all over the West Indies and present many characteristics, which make them worthy of special mention: This year crosses of these two varieties have been made, and it is to be hoped that, not only will a good variety result, but that data will be obtained which may prove useful in helping to trace out the dominant and recessive characteristics of each variety when these crosses are allowed to fertilize themselves.

Several arrows of the better of our varieties are being bagged separately so that they may fertilize themselves, and therefore the resultant seedlings will give some clue to the more prominent characters of these varieties and will be of assistance in the further crosses that will be made.

The planters here freely express their appreciation of the advantages that they have derived from the introduction of these selected varieties and feel that they are now in the possession of a powerful defence against many forms of cane diseases.

In Demerara, up to the beginning of 1905, nearly one-third of a million of seedling canes had been raised by the selection method, and 26,000 of these had been selected for field experiments. A few hundred have been selected from these for continued experiments and practically every estate in the colony has its experimental plat. It need only be stated that at least 12,000 acres are being cultivated in new seedling varieties, to show that planters fully appreciate what has been done for them in the matter of new varieties of canes.

At Jamaica a large number of seedlings have been successfully raised and several others have been introduced. B 208 is extensively cultivated on an estate scale and it is now evident that the splendid qualities of this cane are the outstanding features of the trial plats there, for it has given nearly double the quantity of canes per acre produced by the older kind.

At Barbados during the last five years, over 20,000 varieties of seedling canes have been raised and planted out, but less than one 
per cent of these has stood the stringent tests of field and chemical selection applied. Seedling canes were brought into early prominence here owing to the failure of the Bourbon cane through attacks of fungoid disease, and they have shown that they are capable of considerable resistance to attacks of disease and at the same time give a larger yield of sugar per acre. Many of these seedlings have been distributed to other West Indian Islands.

The Hon. Dr. Francis Watts in Antigua states "that by means of the introduction of new varieties of canes the planter has now an opportunity of selecting his canes for particular soils and situations. In this way, he may not necessarily select that cane which has done best on the average of the whole of the experiments, but his own observation may have led him to see that some particular cane will prove suitable for some special condition and he selects suitable canes accordingly."

The Imperial Department of Agriculture for the West Indies has been the means of raising several thousand seedlings every year, and it is to be hoped that the seedlings obtained by direct hybridization will lead to varieties of sugar cane, the pedigrees of which will be known, which will prove of commercial importance to producers of sugar.

It is fully realized that it is necessary to improve the crops by breeding continually for greater vigor and hardiness and that definite qualities can be induced and intensified so long as systematic attention is directed solely towards this aim.

Over 20,000 plants (tops and portions of stems) are annually exported from Barbados to other West Indian islands, in all of which the area under seedling canes is gradually extending, and it is hoped that a general improvement of the sugar industry will result from the continued conjoined efforts of the experimenters and members of the planting community.

\section{AMERICAN WORK IN BREEDING PLANTS AND ANIMALS.}

By Willet M. Hays, Assistant Secretary of Agriculture, Washington, D. C.

\section{GENERAL SURVEX.}

Nowhere else in the world is there so marked a movement to organize for the improvement of plants and animals as in the United States. Here the value of the rare animal or plant which has very exceptional breeding power is coming to be generally known. Our nation and our states are coming to recognize that hybridizing is a most powerful agency which can be used scientifically in the preparaation of materials that will serve as a basis from which to select other animals and plants with exceptional efficiency, which may be used to breed new varieties or families.

America is ready to support the necessary scientific investigations to develop and demonstrate how best to attack the problem of 